\title{
The use of solar dryer to control insect infestation in stored grains in Ghana
}

\author{
J.M. SEIDU ${ }^{1}$, G.W.K. MENSAH ${ }^{1}$, V. K.ZAH ${ }^{1}$, S.A.A. DANKWAH ${ }^{1}$, \\ W.K.J. KWENIN ${ }^{1}$ and A.A. MAHAMA ${ }^{2}$ \\ ${ }^{1}$ University of Education-Winneba, College of Agriculture Education, Department of Agriculture Mech. \& \\ Engineering, Box 40, Mampong-Ashanti. \\ ${ }^{2}$ University of Ghana, Legon. \\ * Corresponding author, E-mail: seidujames@yahoo.ca, Tel: 233-208748765.
}

\begin{abstract}
A study was carried out to assess the effectiveness of a simple solar dryer, built from local materials, to control cowpea bruchids, Callosobruchus maculatus (Fabricuis) and maize weevils, Sitophilus zeamais (Motsch.) in infested cowpea and maize. The effect of the heat generated in the solar dryer on the mortality of the insects, viability of the cowpea and maize seeds and the emergence of F1 progeny of $C$. maculatus and $S$. zeamais were the parameters assessed. The result obtained showed the reliability of the simple, low cost solar dryer in controlling the insects to an appreciable level. Complete (100\%) mortality was obtained when the infested cowpea and maize were placed in the solar dryers, for 60 minutes and 120 minutes, respectively. The highest mean percent seed viability of the infested cowpea was $66.4 \%$ after being exposed for 120 minutes in the solar dryer and least viability was $48.5 \%$. However, the mean percent seed viability of the infested maize decreased from $85 \%$ after 30 minutes of exposure in the solar dryer to $59.0 \%$ after 4 hours. The test indicated that exposure of the seed to the heat in the solar dryer reduced viability. The control for both cases gave higher percentage seed viability $73 \%$ and $86 \%$ for cowpea and maize, respectively. The period of exposure of the infested grains in the solar dryer for one hour or more also effectively reduced the number of F1 progeny that emerged from the stored grains. The result for solar-treated seeds was only effective as post-harvest reduction in weevil injury and may not be viable for planting due to loss in germination.
\end{abstract}

(c) 2010 International Formulae Group. All rights reserved.

Keywords: mortality, viability, F1 progeny, C. maculatus, S. zeamais.

\section{INTRODUCTION}

In developing countries such as Ghana, substantial quantities of food grains are often lost through damage caused by insect pests due to inefficient storage management systems. Insect pest are among the various biological factors that affect the storage or preservation of cowpea and maize. In Ghana, large quantities of food grains are lost especially at the subsistence farmer's level or rural level due to poor storage practices or poor post-harvest handling processes or techniques. The heaviest losses are caused by biological factors.

The insect pests which cause losses and deterioration to stored cowpea are the cowpea bruchids which include Callosobruchus maculatus (Fabricius), Callosobruchus 
chinensis (L), Acanthoscelides obtectus (Say), Bruchidius atrolineatus (Pic) and Zabrotes subfasciatus (Boheman). Stored maize are destroyed by the maize weevil, Sitophilus zeamais (Motsch) and the larger grain borer, Prostephanus truncatus (Horn).

Post-harvest losses may be as high as $20 \%$ by weight of grains harvested by the average Ghanaian farmer, (Ofosu, 1995). On a global scale, it is estimated that over two million tonnes of grains are destroyed annually by insects, mould, rodents, birds and other pests, (FAO, 2005). It is also known that about $35-45 \%$ and $10-30 \%$ of the total cowpea and maize produced annually are lost through insect infestations respectively, (CRI, 2002). It is also noted that about $20-30 \%$ of grains produced in Africa are lost annually through insect attack (Raemaeker, 2001). This shows that the solution to the problem of food shortage does not rest solely in increased food production but also in minimizing food losses during harvesting and handling through storage to marketing or consumption.

Food preservation skills and technologies are very vital in a region where $30 \%$ of the food grown perishes before it reaches the market centres. To ensure sustainable quality in post harvest handling of grains, there is the need to train many women, especially those in the low income group, in food preservation, appropriate technology and management (CTA, 2005).

Till date, no effective method of preservation has been devised to safeguard the huge post-harvest losses in most agricultural crops. As a result, maize and cowpea also suffer a great deal from insect infestation and other related pests. Improper drying methods leading to loss of quality, reduction in quality and nutritional components as well as viability, are some types of losses suffered by our farmers and marketing agents countrywide, (Chima, 2007)

The use of synthetic insecticides and plant extracts have been found generally to be the most dependable and effective method of reducing food grain losses. Most farmers have been introduced to the use of these agrochemicals to preserve their food grains. However, a number of problems are also associated with the use of these chemicals. Notably among the problems are harmful residues on the stored grains if the withdrawal period is not exceeded before they are used. Also, most farmers lack adequate knowledge about proper application of these chemicals due to illiteracy.

Exposure to high temperatures to kill insects in stored food grains has long been known by our farmers. These farmers disinfest stored food grains by heating them over fires. The effectiveness of this fire- heating technique, though very useful to the resourcepoor farmers, the grains can easily be overheated and thus destroy the quality or viability of stored seeds.

Plastic solar heater has been found through entomological studies at Purdue University in the USA to be lethal to various stages of cowpea bruchids in the seeds. Thus, simple dryers that make use of inexpensive and widely available materials may be a useful method to control infestation of cowpea bruchids and the maize weevils in stored food grains.

The main objective of the study was to test the effectiveness of a simple solar dryer built from local materials to control insects in stored grains.

The specific objectives were to determine;

- Mortality of the insect

- Viability of seeds

- Survival eggs and larvae of pest

\section{MATERIALS AND METHODS}

The black-eye cowpea and Dobidi maize varieties (moisture content of $12 \%$ and $14 \%$ respectively) were obtained from the open market (one month after harvest). Two kilogrammes $(2 \mathrm{~kg})$ of each grain contained in one litre kilner jar, were infested with adult Callosobruchus maculatus and the adult 
Sitophilus zeamais, obtained from stockinfested cowpea and maize.

The infested grains were allowed to stand for seven days in the laboratory at room temperature after which the insects were sieved from the grains. The sieved grains were further kept at the Crop Science Laboratory at room temperature and relative humidity until the emergence of adult insects. This served as the stock culture for the study. To prevent the insects from escaping, the mouths of the kilner jars were covered with pieces of white calico cloth and held in place by rubber bands.

A simple solar dryer, measuring 1600 $\mathrm{mm} \times 600 \mathrm{~mm} \times 1400 \mathrm{~mm}$ was used. It was suitably built with 12- units apartment, each measuring $140 \mathrm{~mm}$ x $110 \mathrm{~mm}$ x140 mm with a capacity of 0.9 tons for cowpea and 0.48 tons for maize on daily basis (Figure 1).

The bottom of the panel was lined up with black polythene sheets to trap solar energy and at the same time prevent heat loss. The top of the dryer was covered with nylon net and transparent polythene sheets, strong enough to withstand high temperatures. Each unit was provided with a thermometer, suspended by means of a thread.

Temperature in the solar dryer was read at pre-determined times of 15, 30, 45, 60, 90, 120, 180 and 240 minutes.

\section{Treatment}

The study was undertaken using Complete Randomized Design with six treatments which were replicated four times. Each treatment had a corresponding control. In all, thirty polystyrene bottles were filled with $1 \mathrm{~kg}$ each of the cowpea and maize grains, respectively.

The experiment was done on different days (from May $14^{\text {th }}$ to $28^{\text {th }}$ of June, 2009) starting from the hours of 9.00 through 13.00 (GMT) each day. Each treatment sample was randomly poured directly into each divided unit of the dryer and covered with a nylon mosquito net of $1.0 \mathrm{~mm}$ diameter to prevent the insect from crossing into other units.
In treatment 1 (T1), $1 \mathrm{~kg}$ of each infested grains was placed in the solar dryer for 15 minutes and 30 minutes (for cowpea and maize, respectively). At the end of the exposure time, the temperature was recorded.

Treatment 2 (T2) was similar to the first one except that the infested grains placed in the solar dryer were left for 30 minutes and 60 minutes (cowpea and maize respectively) after which the temperature reading was again recorded.

In a similar way, treatments $3,4,5$ and 6 were set for periods of 45, 60, 90, 120, 180 and 240 minutes after which the corresponding temperature readings were recorded. The experiment was mounted for four hours each day.

\section{Solar disinfestation technique}

Fifty adults of cowpea bruchids and maize weevils, (0-7 days old) were taken from the stock culture and added to $1 \mathrm{~kg}$ of the cowpea and maize in each bottle of $250 \mathrm{ml}$ respectively. The insects were allowed to stay on the grain for 24 hours in the kilner jars for the insect to be accustomed to the grain before they were transferred into the solar dryers. The infested cowpeas were left in the solar dryer at pre-determined time intervals of 15 , $30,45,60,90$ and 120, minutes, whilst the infested maize grain where placed in the solar dryer for predetermined periods of $30,60,90$, 120, 180 and 240 minutes. The temperature readings were taken at the end of each time interval. Each treatment was replicated four times. Checks (controls) were also set alongside each treatment.

\section{Mortality in the solar dryer}

After the period of exposure in the solar dryer for the pre-determined time intervals, the insects were separated by sieving the grains. The dead and live insects were counted and recorded. Similarly, the dead and live insects in each check were also assessed and the mortality used to correct the 
mortality in the treatment. The dead insects were detected by pricking with an office pin.

\section{Seed viability}

Seed viability tests were performed on the infested and non-infested seeds soon after exposure. Fifty seeds per each replicate of cowpea and maize were selected at random and placed on wet cotton wool contained in Petri dishes. These were then left on laboratory benches at room temperature and relative humidity for seven days. After seven days, seeds which had germinated were counted and percent seed viability computed.

\section{Emergence of F1 progeny}

After the samples of the cowpea and maize seeds had been taken for the assessment of seed viability, the remaining grains of each treatment were put into 1-litre kilner jars. Clean sheets of white calico were fastened at the mouth of the kilner jars by means of rubber bands. After 21 days of observation, the number of insects that emerged from each treatment was counted and recorded daily until no more insects emerged. Similarly, daily counts of insects that emerged from the control of each treatment were recorded.

\section{Data analysis}

Values obtained were subjected to statistical analysis (Anova $\mathrm{p} \leq 0.05$ (SAS, 1999).

\section{RESULTS}

\section{Temperature changes in the solar dryer}

The temperature showed a sharp rise from $32.7{ }^{\circ} \mathrm{C}$ at $10: 30$ hours to $57.3{ }^{\circ} \mathrm{C}$ at 11:00 hours with the surrounding air temperature $32.3{ }^{\circ} \mathrm{C}$. Thereafter, the increase in temperature was gradual rising to about $59.8^{\circ} \mathrm{C}$ at about $11: 30$ hours before falling to $57{ }^{\circ} \mathrm{C}$ at about 12:00 hours. It was observed that (on sunny days) a high temperature was built up to $71.5^{\circ} \mathrm{C}$ in the solar dryer at $12: 30$ hours with a corresponding outside temperature of $35.9^{\circ} \mathrm{C}$ (Figures 1a \& 1b).

\section{Mean percent mortality of weevils exposed to varying temperatures and times}

The effectiveness of the temperature in the solar dryer and the time of exposure of the infested cowpea and maize on the mortality of the adult weevils are presented in Figures 2a and $2 \mathrm{~b}$ respectively.

\section{Mean percent viability of grains after exposure in the solar dryer}

The result of test on viability indicated a general reduction of viability of the grains placed in the solar dryer for the varying times in comparison with the control seeds (Figures $3 a$ and $3 b$ ).

\section{Mean emergence of $F_{1}$ progeny}

Exposure of infested cowpea and maize seeds for a period of 240mins (4 hrs) led to no emergence and hence a total destruction of weevils. This was the case because longer exposures at temperatures above $40{ }^{\circ} \mathrm{C}$ are lethal to insect pests (Gewinner et al., 1996).

\section{DISCUSSION}

Temperature changes in the solar dryer

The result revealed a rapid build-up of heat energy in the solar dryer as soon as it was placed in the sun. This resulted in the increase in temperature at different times during the day as shown in Figures 1a \& 1b (Maria Crista et al., 2006).

With the cowpea experiment, the temperature showed a sharp rise from 32.30 ${ }^{\circ} \mathrm{C}$ (surrounding air temperature) at 09.00 hours to $49.60{ }^{\circ} \mathrm{C}$ (temperature in the solar dryer) at 09.15 hours (Figure $1 b$ ). Thereafter, the temperature increased gradually to about $61.00{ }^{\circ} \mathrm{C}$ at 10.30 hours (ie 45 minutes of exposure) before falling to $56.00{ }^{\circ} \mathrm{C}$ at about 11.30 hours (i.e. 60 minutes of exposure). The highest temperature of $67.10{ }^{\circ} \mathrm{C}$ in the solar dryer was attained at 12.00 hours (i.e. 90 minutes of exposure) (Seidu et al., 2008). 


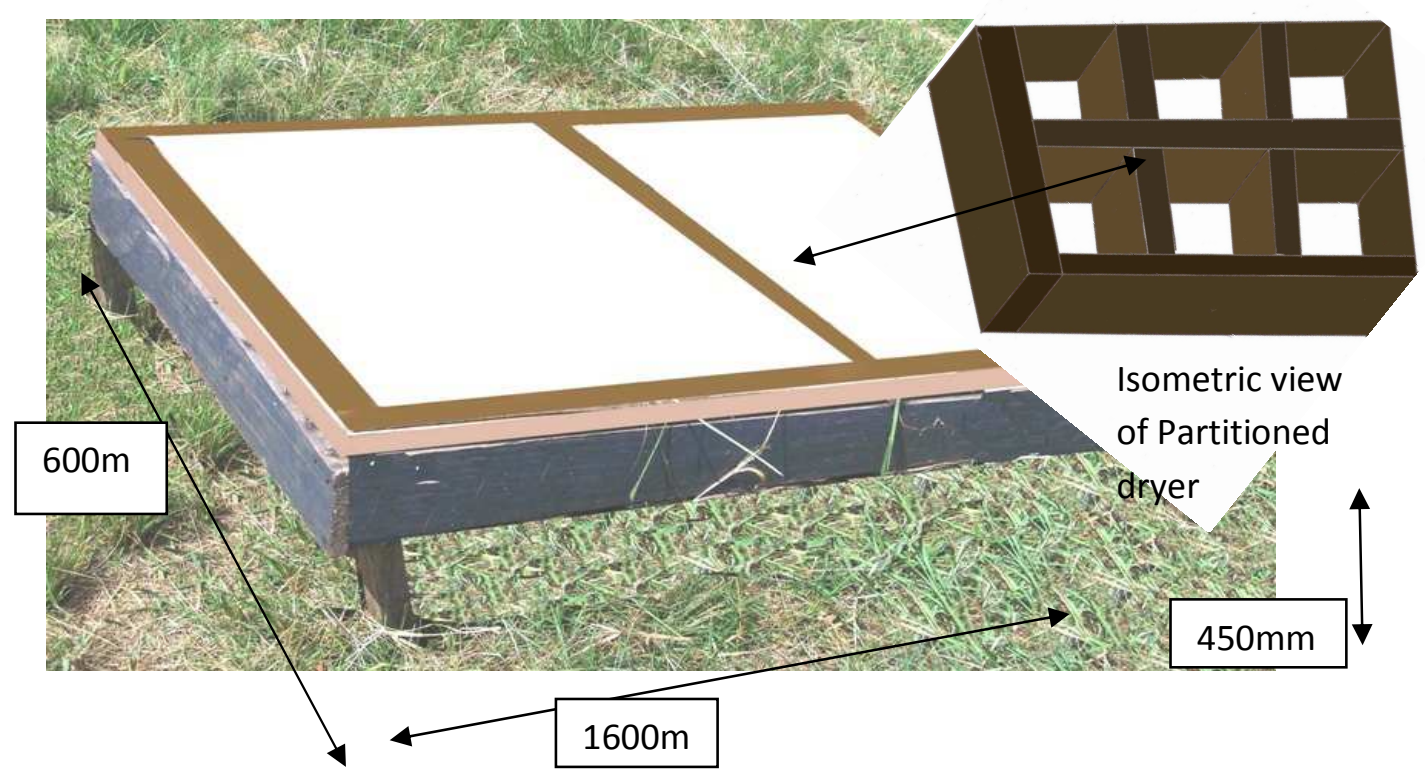

Figure 1: The solar panel used for determining the mortalities of test insects in stored grains.

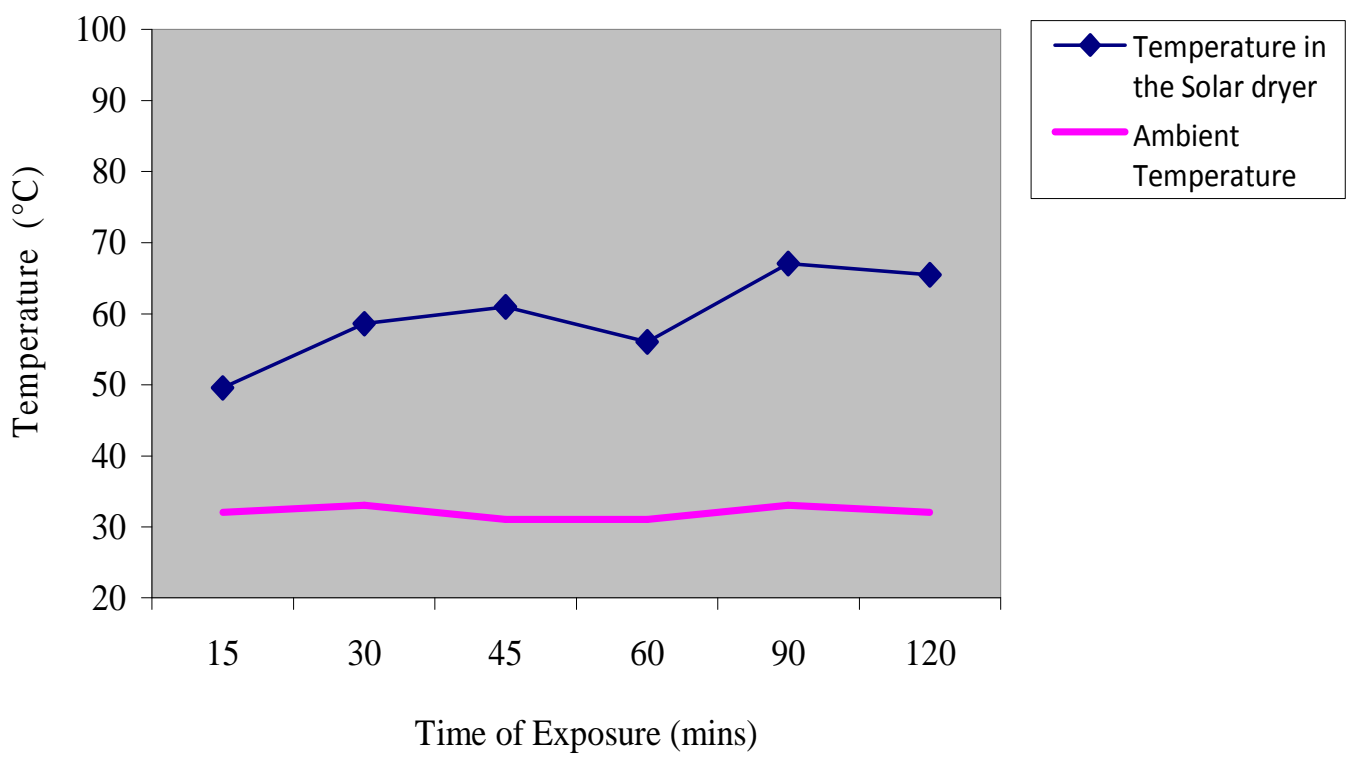

Figure 1a: Mean ambient temperature and mean temperatures inside the solar dryer during exposure of maize seeds. $\mathrm{p} \leq 0.05, \mathrm{Cv}=3.37 \%$, $\operatorname{LSD}(0.05)=3.00$. 


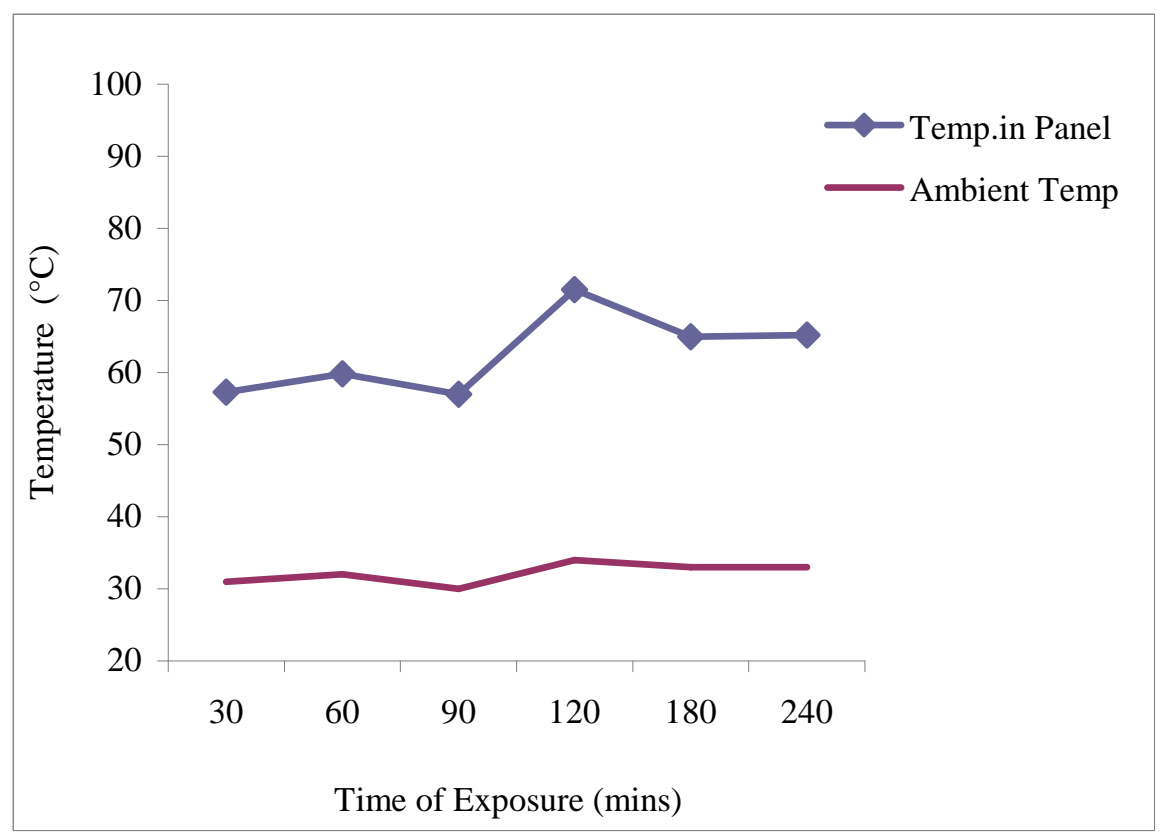

Figure 1b: Mean ambient temperature and mean temperature inside the solar dryers during exposure of cowpea seeds.

$\mathrm{p} \leq 0.05, \mathrm{cv}=3.57, \operatorname{LSD}(0.05)=3.16$.

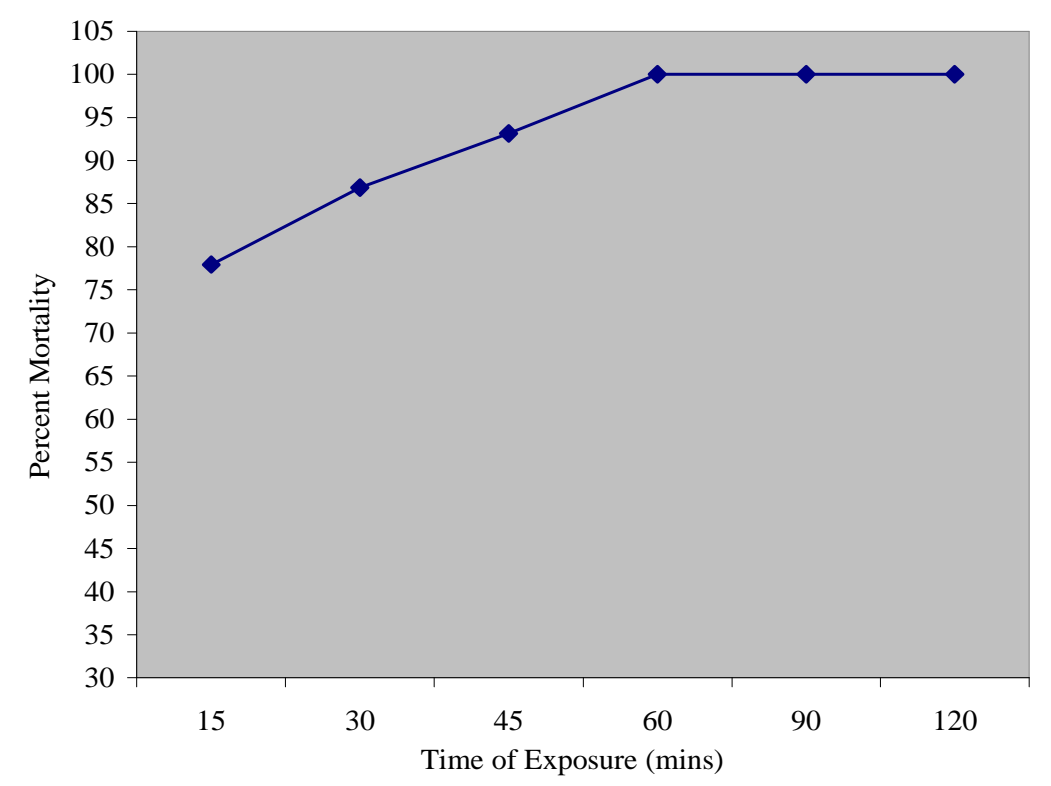

Figure 2a: The mean percent mortality of cowpea weevil during various periods of exposure of infested cowpea in the solar panel.

$\mathrm{p} \leq 0.05, \mathrm{Cv}=2.81 \%$, LSD $(0.05)=3.81$. 


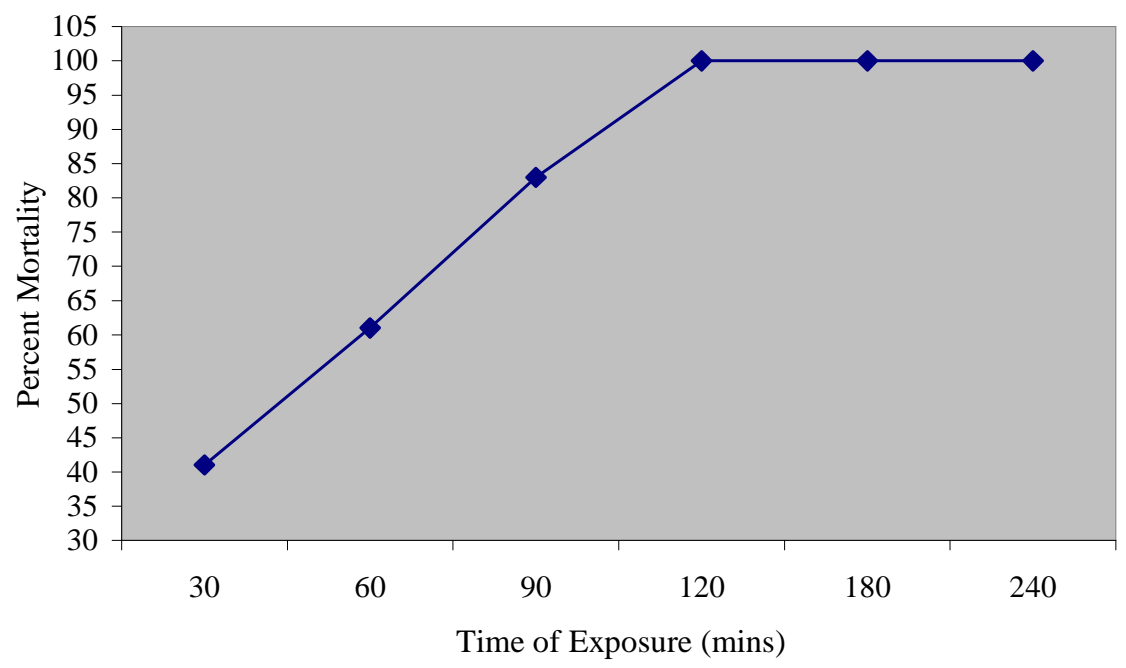

Figure 2b: The mean percent mortality of maize weevils during various periods of exposure of infested maize in the solar panel. $\mathrm{p} \leq 0.05, \mathrm{Cv}=3.83 \%, \operatorname{LSD}(0.05)=2.21$.

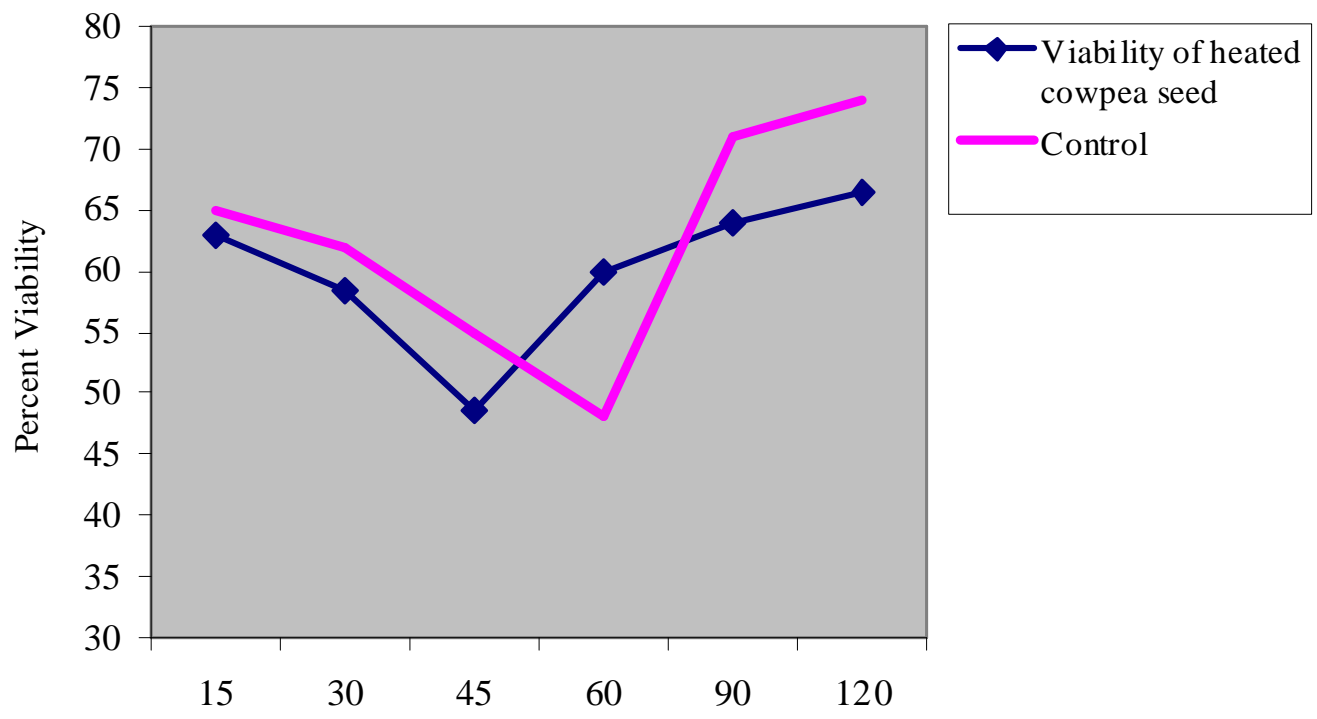

Time of Exposure (mins)

Figure 3a: Mean percent viability of cowpea seed after exposure in the solar dryer. $\mathrm{p} \leq 0.05, \mathrm{Cv}=19.71 \%, \operatorname{LSD}(0.05)=17.56$. 


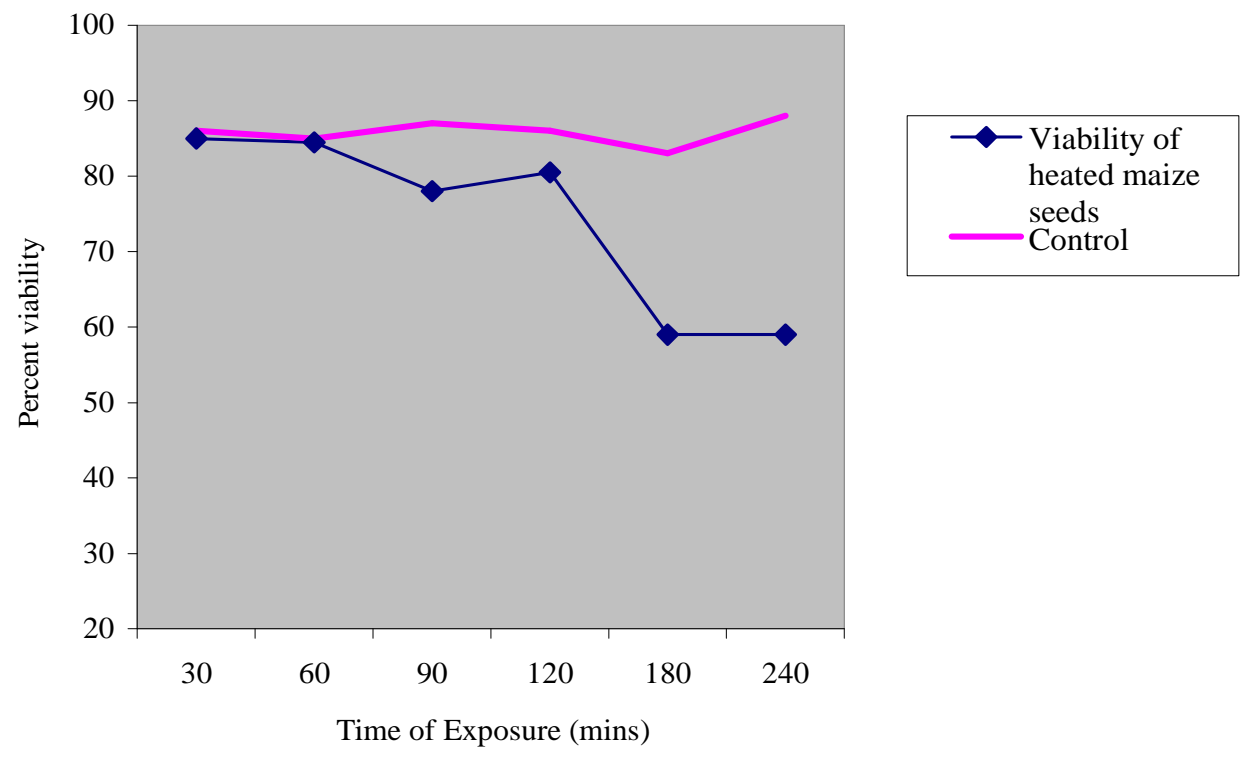

Figure 3b: Mean percent viability of maize seed after exposure in the solar dryer. $\mathrm{p} \leq 0.05, \mathrm{Cv}=11.38 \%, \operatorname{LSD}(0.05)=6.03$.

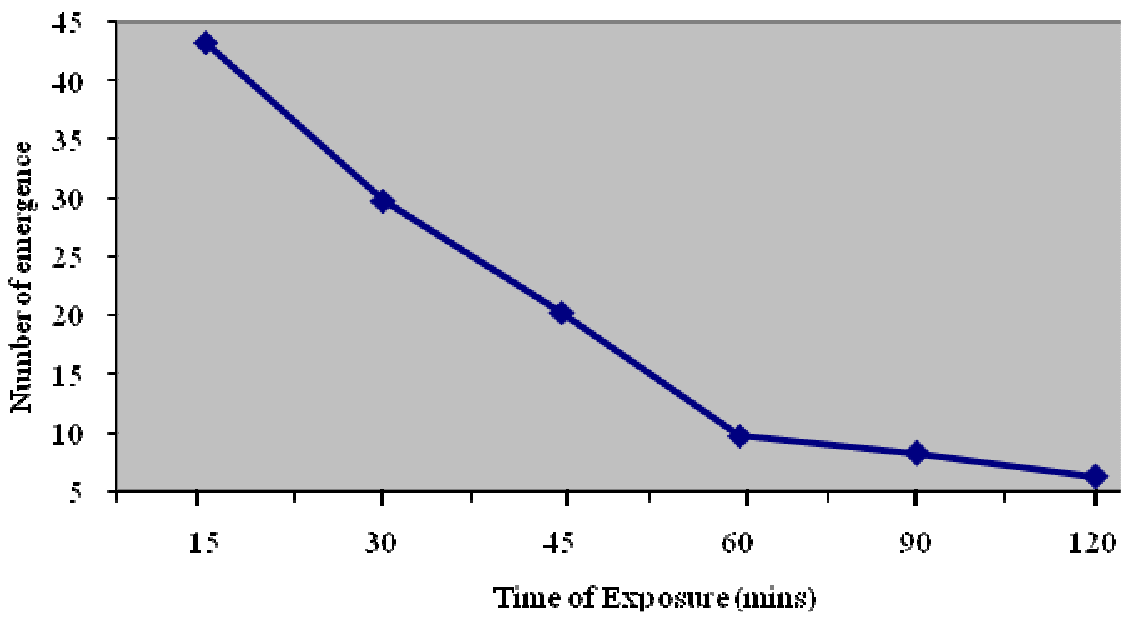

Figure 4a: Mean number of F1 progeny of cowpea weevil. $\mathrm{p} \leq 0.05, \mathrm{Cv}=18.35 \%, \operatorname{LSD}(0.05)=5.33$. 


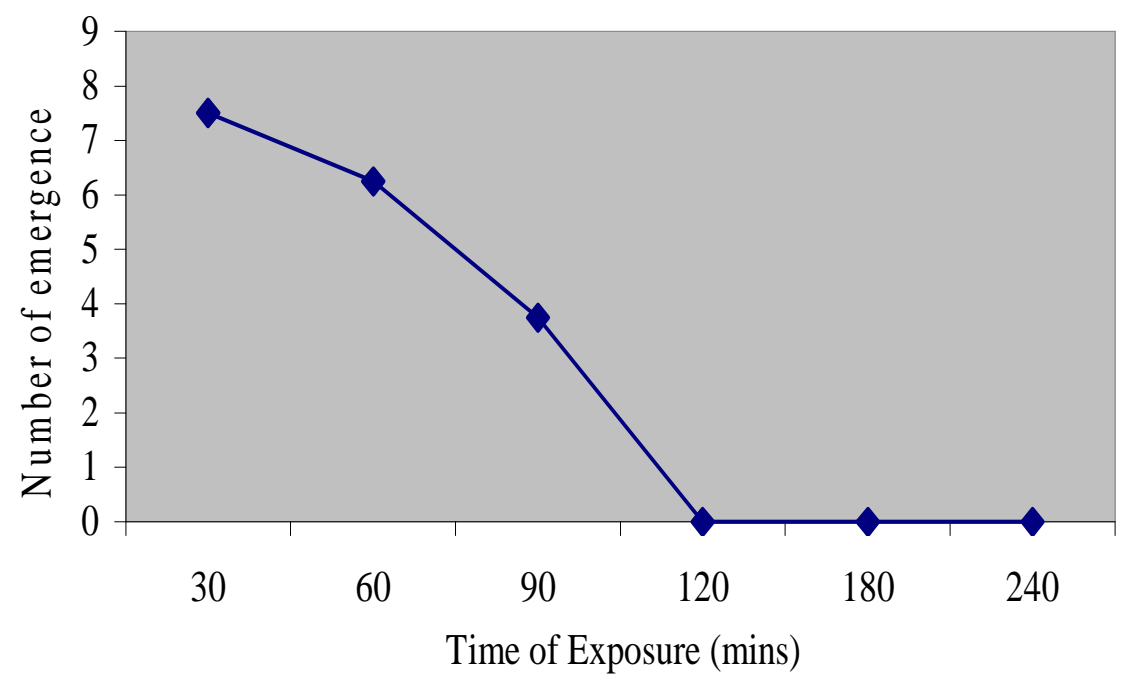

Figure 4b: Mean number of emergence F1 progeny of maize weevil. $\mathrm{p} \leq 0.05, \mathrm{Cv}=15.32 \%, \operatorname{LSD}(0.05)=1.03$.

In the maize experiment, the temperature also showed a sharp rise from 28 to $57.30^{\circ} \mathrm{C}$ from the hours of 10.30 and 11.00 , after only 30 minutes (Figure 1b). Thereafter, the increased in temperature was relatively gradual reaching $59.80{ }^{\circ} \mathrm{C}$ after 60 minutes or at 11.30 hours. This was followed by a fall in temperature to $57.00{ }^{\circ} \mathrm{C}$ after 90 minutes and then an increase to $71.50{ }^{\circ} \mathrm{C}$ after 120 minutes (12.30 hours) and this could be attributed to occasional interruption by cloud cover which might have prevented continuous absorption of heat energy from the radiation in the solar dryer (Seidu et al., 2008) and (htt:/www.cahe.musu.edu./pubs/e-322-htm-).

This indicates that cloud cover could adversely affect the efficiency of the solar dryer. The highest temperatures were recorded at 12.30 but declined at 13.30. The decline in temperature corresponds to declining sunshine intensity and solar radiation as time progressed, This observation is in agreement with (Jackson et al., 1981) who stated that two hours of exposure in solar dryer gave way for temperature to reach its highest amplitude of $75.5{ }^{\circ} \mathrm{C}$ and this was followed by sudden but steep fall in temperature to $46.5{ }^{\circ} \mathrm{C}$ which could also be lethal to insects in the infested grains.

\section{Mortality of weevils exposed to varying temperatures and time}

It was observed that the mortality of the weevils increased in proportion to time that the infested grains were kept in the solar dryer.

Complete mortality of C. maculatus was obtained when the infested cowpea was kept in the solar dryer for 60 and more minutes (Figure 2a) whilst 120 minutes or more were required for complete mortality in S. zeamais (Figure $2 \mathrm{~b}$ ).

When heat treatment is given to stored produce, it controls insects by using temperatures known to be lethal to the insects when such temperatures are maintained for a given period (Gewinner et al., 1996). Solar treated grains showed $100 \%$ mortality of adult insects (Jackson et al., 1981). The trial of (Jackson et al., 1981) showed that the lowcost solar dryer was effective in eliminating all developmental stages of weevils. 
The solar dryer built from local materials for the study was quite effective in causing more than $70 \%$ mortality after 15 minutes of exposure and $100 \%$ mortality at 60 more minutes or.

\section{Viability of grains after exposure in the solar dryer}

As the heat accumulated in the solar dryer, the viability of the seeds became affected by the generated heat. Viability of the maize seeds therefore decreased as the heat increased with time of exposure of the infested maize (Figure 3b). However, the trend was different for that of infested cowpea seed (Figure 3a). The viability of the cowpea seeds decreased steadily up to 45 minutes of exposure. For some reasons which cannot be simply explained, the viability of the cowpea increased to $60 \%$ after 60 minutes of exposure of infested cowpea in the solar dryer.

The highest mean percent seed viability of the infested cowpea was $66.4 \%$ after being exposed for 90 minutes and the lowest seed viability was $48.5 \%$ after 45 minutes of exposure in the solar dryer.

However, the mean percent seed viability of the infested maize decreased from $85 \%$ after 30 minutes to $43.5 \%$ after 4 hours of exposure in the solar panel.

The test indicated that exposure of the seed to the heat in the solar dryer reduced viability. Germination test after three months of storage revealed a significant difference between solar treated and the control, in which germination ranged from $81.1 \%$ to $90.2 \%$ (IPM/CRSP, 1998). The results for the solar treated seeds were only effective as postharvest reduction in weevil injury and not for seed due to loss in germination. In contrast, some of the control seeds which were only exposed to environmental temperature also registered low germination counts $(60 \%$ and $70 \%$ for cowpea and maize respectively). This meant that it was not the solar heat that caused the low seed viability but rather the seeds used for the research were not full-proof viable as some of them showed signs of mouldiness.

Higher levels of mortality ( $83 \%$ ) of the weevil and viability of the maize seeds $(78 \%)$ were obtained when the maize seeds were exposed in the solar dryer for 90 minutes at 57 ${ }^{\circ} \mathrm{C}$. In a similar way, complete mortality $(100 \%)$ of the cowpea weevils and a high level of seed viability $(66 \%)$ were obtained when the cowpea seeds were solar heated for 120 minutes at $65.5{ }^{\circ} \mathrm{C}$. Seeds which were kept in solar dryer for 1 hour or less were able to germinate but those kept for 2 hours or more did not germinate (Jackson et al., 1981).

\section{Emergence of F1 progeny of the weevils}

The results showed that the application of the solar dryer technique in controlling the weevil infestation in the seeds was effective to an appreciable level (Figures 4a \& 4b). The observations revealed that the extent of control of the insects in the seeds corresponded with duration of exposure of the seed to solar radiation. Exposure of the infested cowpea seeds in the solar dryer for 15 and 30 minutes significantly $(\mathrm{P}=0.05)$ recorded higher number of $\mathrm{F} 1$ progeny of the bruchids than when the seeds were exposed for 60, 90, and 120 minutes (Figure 4a). For the maize weevils, the number of $F 1$ progeny which emerged from the solar heated maize seeds were very low (Figure 4b) in comparison with the cowpea weevils probably because most of the eggs which were laid were destroyed. There was no emergency of F1 progeny of the maize weevil when the infested maize seeds were kept in the solar dryer for 120 minutes or more.

The study has shown that the longer the infested seeds were kept in the solar dryer, fewer numbers of F1 progeny emerged. Research has shown that most stored product insects are known to succumb to death at about $40{ }^{\circ} \mathrm{C}$ and $45{ }^{\circ} \mathrm{C}$ and that 1 hour of exposure at $45{ }^{\circ} \mathrm{C}$ or more is sufficient to wipe out all the infestation of any developmental 
stages of insects (Gewinner et al., 1996; Kick et al., 1992). The emergence of some F1 progeny in the present study seemed to suggest that not all the developmental stages of the test insects were destroyed by heat generated in the solar dryer.

The range of temperature suitable for insect development is narrower, and that most insects are unable to complete their life cycle at temperatures outside the range of $10{ }^{\circ} \mathrm{C}$ and $45{ }^{\circ} \mathrm{C}$ because the insects become inactive substantially (Field, 1992).

The present study has therefore demonstrated that if infested grains are kept in the solar dryer for up to 1 hour or more, the amount of heat generated can eliminate the existing insect infestation and considerably reduced the emergence of $\mathrm{F} 1$ progeny.

\section{Conclusion}

One major area of concern is the degradation or loss of nutritional value of stored grain for feed and for feeding farm animals especially poultry. During the major farming season, maize and cowpea are cheap but become very expensive during the lean season. The high costs of cereals make chicken and eggs expensive. The effectiveness of the solar dryer in killing weevils in maize and cowpea respectively will eventually lead to negligible post-harvest losses and consequently low cost of food and feed for humans and farm animals and hence low cost of meat and eggs.

The results of the study showed the effectiveness of the solar dryer in generating enough heat to cause mortality of the insects without drastically reducing the viability of the seeds.

The period of exposure in the solar dryer was able to effectively reduce the number of F1 progeny that emerged from both types of grains during storage. The results obtained from the study have demonstrated that if infested grains are kept in the simple solar dryer for about an hour at the right time of the day, enough heat can be generated to completely disinfest the grains without causing much damage to the embryos of the seeds.

Again, considerable reduction in damage due to F1 progeny can be achieved without resorting to the use of insecticide.

Farmers could use the technology during brighter days (no clouds cover) to disinfest maize exposed for 90 minutes and that of cowpea for 120 minutes to obtain higher levels of weevil mortality and seed viability at temperatures of $57{ }^{\circ} \mathrm{C}$ and $68{ }^{\circ} \mathrm{C}$ for maize and cowpea seeds respectively.

With this type of solar dryer, 0.9 tonnes of cowpea and 0.48 tonnes of maize can be disinfested of weevils in a day. This technology can easily be handled by our local farmers. However, it is recommended that the design of the solar dryer would have to be improved for easy handling and operation by an individual farmer or producer.

\section{REFERENCES}

Chima Igwe. 2007. file//F: /regional reportpostharvest loss reduction in Nigeria.html Crops Research Institute (CRI), (2002). Fourth National Maize and Cowpea Workshop, organized by GGDP at Kwadaso Agriculture College, Kumasi Ghana. March 6-10, 2002 1-2.

CTA. 2005. The Storage of Food Grains and Seeds. Annual Report. Macmillan Publishers: London, U.K; 20-24.

FAO. 2005. Prevention of post-harvest food losses. Publication Division of FAO, UN, Rome. 19-41.

Fields PG. 1992. The control of stored product insects and mites with extreme temperatures. Journal of Stored Products Research, 28: 89-118.

Gewinner J, Harnisch R, Muck O. 1996. Manual on the Prevention of PostHarvest Grain Losses. Post-Harvest Project. Publishers Eschborn: Germany; 97-270.

Htt://www.cahe.musu.edu./pubs/e-322-htm- 
IPM/CRSP. 1998. On- farm post-harvest management of bruchids in beans and cowpea. Fifth Annual Report, 11: 4-5.

Jackson LA, Matteson PC. 1981. Effect on solar drying periods of beans on seed viability, cooking time and injuriousness of Acanthoscelides obtectus. African Crop Science Journal, 6(4): 417-421.

Kitck LW, Ntoukam G, Shade RE, Wolfson JL, Murclock LL. 1992. A solar heater for disinfesting stored cowpeas on subsistence farms. Journal of Stored Products Research, 28: $261-267$

Maria C, Martenez S, Cesar EA. 2006. Construction and use of solar coffee bean dryer in Chiapas. Granada Conference paper, July, 2006.
Ofosu A. 1995. Maize storage improvement programme. Proceedings of Crop Research Institute. Ghana Workshop. 4 15.

Raemaekers RH. 2001. Crop Production in Tropical Africa. Directorate General for International Co-operation, Brussels (Begium), 344-347.

SAS.1999. Statistical Analysis System. Users Guide. SAS/STAT; version $8^{\text {th }}$ Edition. SAS Institute Inc.: Carry, N.C. USA

Seidu JM, Tevor WJ, Mahama AA, Kotei R, Amoah RS. 2008. Suitability of locally constructed solar dryers for vegetable drying. Ghana Journal of Science Association, 10: 50-58. 